\title{
Arbor
}

\section{Unir y separar: Algunos efectos socio-religiosos de la acción inquisitorial durante el reinado de Isabel $\mathrm{I}^{1}$}

\section{María del Pilar Rábade Obradó}

Arbor CLXXVIII, 701 (Mato 2004), 67-86 pp.

Durante el reinado de Isabel I se inició la andadura de la Inquisición, institución que estaba destinada a dejar una profunda huella en las tierras hispánicas. La actividad del Santo Oficio tuvo, desde sus momentos iniciales, importantes efectos socio-religiosos; entre ellos, los derivados de la ruptura de la cohesión que hasta ese momento había reinado entre las diversas comunidades judaizantes que salpicaban los reinos sobre los que gobernaba la soberana.

Evidentemente, se trataba de uno de los objetivos de la Inquisición, que identificaba esa ruptura con el comienzo del fin de la presencia criptojudía, debido al carácter comunitario de muchos de los ritos mosaicos, que perdían su sentido si eran practicados de forma aislada por los falsos conversos. Asimismo, parecía lógico suponer que los judaizantes, desprovistos además del apoyo de los suyos, no tardarían en desmoralizarse, regresando al redil de la Iglesia, convencidos de que su opción religiosa carecía de futuro.

Pero si la acción del Santo Oficio contribuyó a separar a los criptojudíos, mostrándoles los peligros que corrían si no cortaban los lazos que les unían entre sí, también contribuyó (o pretendió contribuir) a unir, pues les señaló el camino de la asimilación con los cristianos viejos, el único posible si deseaban evitar el embate inquisitorial. Así pues, la Inquisición fue utilizada para romper viejas solidaridades, pero también para intentar crear otras nuevas, si bien este segundo proceso resultó ser 
especialmente complejo, debido a las resistencias con las que se enfrentó, provenientes tanto de los cristianos nuevos como de los viejos.

\section{Separar: la quiebra de la solidaridad de las comunidades criptojudías}

La solidaridad era un elemento fundamental para el mantenimiento de las comunidades criptojudías ${ }^{2}$. Los fuertes vínculos que se establecían entre sus miembros permitían el mantenimiento del sentido comunitario de los ritos judíos ${ }^{3}$, como también garantizaban el necesario secreto ${ }^{4}$ so- $^{-}$ bre la realización de las prácticas judaizantes, al tiempo que ofrecían ciertas posibilidades de ayuda y protección mutuas. Sólo gracias a la solidaridad y al secreto podían mantenerse vivas las comunidades criptojudías, pues los ritos mosaicos impregnaban los actos de la vida cotidia$\mathrm{na}^{5}$, y únicamente podían realizarse si los judaizantes contaban con los necesarios apoyos en su círculo más íntimo (parientes, criados, vecinos...); si esos apoyos fallaban, era muy difícil cumplir con el judaísmo, aunque las condiciones extremas en las que se movían en ocasiones los criptojudíos hacían que muchas veces se considerara suficiente la voluntad de cumplir con los ritos y preceptos del mosaísmo, pues el realizarlos de forma efectiva implicaba excesivos peligros ${ }^{6}$. Así pues, las comunidades judaizantes crearon estrechos vínculos, destinados a permitir una práctica lo más completa posible de la ley mosaica.

La familia jugaba un papel fundamental en el mantenimiento de la solidaridad en las comunidades criptojudías ${ }^{7}$. Esta realidad fue ya claramente percibida por la Inquisición, que se cebó en determinados grupos familiares especialmente vinculados con el criptojudaísmo, posiblemente como consecuencia de una estrategia que pretendía romper la cohesión de esas familias ${ }^{8}$, para socavar así los cimientos de la comunidad judaizante de la que formaban parte, buscando su destrucción y la integración de sus miembros en la sociedad cristiana.

Se puede traer a colación el caso de la familia de Pedro Núñez, regidor de Toledo. Su mujer, de nombre desconocido, era reconciliada. Sus dos hijos, Francisco y Aldonza, pasaron, tras ser reconciliados, por sendos procesos, ya que los inquisidores consideraron que las confesiones sobre las que se habían basado sus reconciliaciones habían sido falsas, siendo su único objetivo evitar la acción del Santo Oficio. Francisco se llevó la peor parte, pues acabó siendo relajado al brazo secular; más afortunada fue su hermana, que, tras resistir bravamente la tortura, fue ab- 
Unir y separar: Algunos efectos socio-religiosos...

suelta, aunque hubo de abjurar «de vehementi». Un tercer hijo del regidor, de nombre Alfonso, fue también enjuiciado por la Inquisición, terminando su proceso con la misma sentencia con la que se saldó el de su hermana ${ }^{9}$.

Un segundo ejemplo, el de la familia de Rodrigo de la Peña la Puebla de Alcocer, que hubo de enfrentarse a dos procesos inquisitoriales, el primero de ellos cuando todavía era menor de edad. El segundo, cuando era ya adulto, ofrece abundante información sobre las conflictivas relaciones que tanto él como varios parientes suyos tuvieron con el Santo Oficio ${ }^{10}$. Su padre, el arrendador Álvar González de Puerto Peña fue condenado en ausencia a ser relajado al brazo secular, mientras que su madre, Inés González, era reconciliada. Sus hermanos, el cardador Fernando de la Peña y Mencía de la Peña, también eran reconciliados; además, Mencía estaba casada con Juan Sánchez, preso en las cárceles inquisitoriales cuando Rodrigo se enfrentó a su segundo proceso.

Pero no acababan ahí las desventuras familiares, pues los tíos, tanto paternos como maternos, de Rodrigo de la Peña también le dieron trabajo al Santo Oficio. Entre los hermanos de su padre hay que destacar el caso de García de Puerto Peña, vecino de Herrera, que acabó sus días en las hogueras inquisitoriales; tal vez más afortunado fue Diego González de Puerto Peña, igualmente vecino de Herrera, cuyos problemas con el Santo Oficio no fue capaz de precisar su sobrino, dudando si tan sólo fue reconciliado, o si corrió la misma suerte que su desgraciado hermano. Varios (¿quizá todos?) de los hermanos de su madre fueron también reconciliados: Ruy, Fernando, Elvira, Catalina y Beatriz; esta última estaba casada con García Fernández de Erena, cuya familia tampoco permaneció al margen de la actividad inquisitorial. En la misma situación estaba la familia de Isabel Hernández, mujer del propio Rodrigo de la Peña, que, para no desentonar ni con su parentela ni con la de su marido, también era reconciliada.

Pero había casos peores: los de aquellos que tenían, además de un nutrido grupo de parientes que habían tropezado con la Inquisición, familiares que habían logrado huir de la Península para vivir públicamente como judíos. Leonor Álvarez, mujer de Juan de Haro, estaba en esa situación. Leonor había sido impuesta en el judaísmo por su prima Inés, casada con el sastre Antón, compartiendo con ella sus prácticas heréticas durante años, hasta que la pareja escapó a Constantinopla, donde vivían desde hacía algún tiempo como judíos; igualmente era prima suya Isabel, mujer de Juan Lobón, que, con su hija Leonor, también 
se había instalado en Constantinopla, por supuesto para poder vivir como judías ${ }^{11}$.

Se hace evidente cómo, en efecto, el criptojudaísmo era, frecuentemente, una cuestión familiar. Así, el proceso contra Rodrigo Alonso Aravalle le presentaba judaizando en unión con su esposa, su hijo y su nue$\mathrm{ra}^{12}$. Por su parte, Mayor, mujer de Juan de Segovia, realizaba los ritos y ceremonias del mosaísmo en compañía de algunos de sus parientes más próximos: sus tías, Leonor y Juana González, y su abuela, Violante Álvarez ${ }^{13}$... Hasta tal punto llegaron las cosas, que incluso se ha podido localizar en los fondos documentales del tribunal de Toledo un proceso incoado contra una cristiana vieja, Marina, casada desde jovencita con un converso mucho mayor que ella, el vecino de Madrid Alonso Rodríguez de Seseña ${ }^{14}$. Parece que los inquisidores consideraron que su marido ejercía tal influencia sobre Marina, que podría haberla inducido a judaizar, si bien lo cierto es que los vagos testimonios recogidos contra ella, que se limitaban a señalar que purgaba la carne y quitaba la landrecilla de la pierna, al tiempo que callaba lo que sabía de otros herejes, hicieron que su proceso terminara en absolución.

Para los criptojudíos era muy importante el mantenimiento de una fuerte endogamia ${ }^{15}$, que les llevaba a establecer vínculos matrimoniales con aquellos que consideraban que compartían sus creencias, soslayando las uniones conyugales con los cristianos viejos, pero igualmente con los conversos a los que creían cristianos sinceros; esa fuerte endogamia contribuía, también, a incrementar los vínculos de solidaridad entre aquellos que formaban parte de un mismo círculo criptojudío, a la par que ayudaba a mantener el necesario secreto sobre las prácticas religiosas de sus miembros.

Bien es verdad que la práctica de la endogamia no siempre producía los resultados apetecidos, pues, en ocasiones, los cónyuges no se comportaban de la forma esperada; por ejemplo, el ensayador Juan de Toledo se encontró con la desagradable sorpresa de que su mujer se negaba a judaizar, lo que ocasionó frecuentes peleas entre la pareja ${ }^{16}$. Por su parte, Pedro de Villegas no era criptojudío, pero consentía que en su casa se judaizara, pues su mujer se mantenía fiel a las creencias de sus ances$\operatorname{tros}^{17}$. Si se han de creer las palabras de Juana Ruiz, mujer de Gonzalo de Villarrubia, sólo judaizaba cuando estaba en compañía de los parientes de su marido, por cumplir con ellos, de modo que cuando la pareja se trasladó a Daimiel, la localidad natal de ella, dejó de realizar los ritos y ceremonias mosaicos ${ }^{18}$. 
Unir y separar: Algunos efectos socio-religiosos...

Como es evidente, la ruptura de la endogamia provocaba problemas y quebraderos de cabeza a los judaizantes; así le sucedió a Juana Rodríguez, mujer de Juan Rodríguez. Criptojudía desde los trece años, cuando su padre la impuso en el mosaísmo, se mantuvo fiel a la religión de sus mayores hasta que casó en segundas nupcias con un cristiano viejo. Esa circunstancia obligó a Juana a ocultar a los ojos de su marido sus erradas prácticas religiosas, aunque tampoco terminó totalmente con ellas, entre otras cosas porque siguió relacionándose con varias vecinas criptojudías, como Isabel de Córdoba, que la ayudaba para que pudiera seguir judaizando ${ }^{19}$

Por supuesto que esa endogamia no dejaba de acarrear problemas a los que la practicaban, pues la pertenencia a determinadas familias implicaba un mayor riesgo de caer en las manos del Santo Oficio, bien como consecuencia de la presencia de sólidos testimonios incriminatorios, bien, simplemente, por el hecho de pertenecer à grupos familiares cuya ortodoxia religiosa era puesta en entredicho de forma global porque varios de sus miembros habían tropezado con la Inquisición, algo que solía desatar rumores y calumnias, a los que los inquisidores prestaban con frecuencia demasiado crédito.

Pero las familias criptojudías no siempre eran capaces de mantenerse unidas, y a veces habían de enfrentarse a las rupturas provocadas por las delaciones de sus miembros, que resultaban especialmente peligrosas para los afectados. Se puede traer a colación el caso de Sancho de Molina, vecino de Toledo, que delató las prácticas judaizantes de su madre y hermanos; Sancho incriminó también a personas ajenas a su ámbito familiar, como el escribano público de Sevilla Francisco Sánchez, del que había sido criado, y que fue quien le impuso en el judaísmo; el vecino de Sevilla Lope de Carmona o el clérigo Andrés González, vecino de Guada$\operatorname{lupe}^{20}$.

Como es evidente, esas delaciones estaban, frecuentemente, motivadas por el pavor que el Santo Oficio infundía a los cristianos nuevos, que una vez que se sentían atrapados por su potente maquinaria optaban muchas veces por confesar sus erradas prácticas, a la par que denunciaban a los que con ellos las habían realizado, sabiendo que los inquisidores sólo tendrían piedad si esa denuncia se producía. La situación era especialmente peligrosa en el caso de los más jóvenes, pues precisamente su juventud, y el hecho de estar bajo la autoridad y el ascendiente de parientes adultos, hacía que esas denuncias tuvieran un efecto más inmediato sobre los inquisidores, predispuestos a considerar que si habían 
obrado mal era por la negativa influencia que se había ejercido sobre ellos. Así, Isabel de Montalbán, que era menor de edad cuando fue juzgada, salió con bien del trance gracias a que su abogado defensor hizo mucho hincapié en su juventud, y gracias también a que la rea denunció a su madre, que era quien la había impuesto en el judaísmo ${ }^{21}$.

Estas delaciones hicieron que, poco a poco, se fuera instalando en el seno de estas familias una cierta desconfianza, que dio lugar a situaciones un tanto peculiares. El mismo Sancho de Molina, al que se ha aludido más arriba, se vió afectado por esa situación, pues aunque su mujer también era conversa, como le parecía fiel cristiana se afanaba por ocultarla sus prácticas religiosas, ante el temor de que ella pudiera denunciarle. La frecuencia con que se producían esas delaciones aconsejó a los criptojudíos insistir en el secreto, en una doble vía: por un lado, se cuidaban de que los niños no participaran en sus prácticas, produciéndose la iniciación de los vástagos cuando se consideraba que habían llegado a la edad de la discreción ${ }^{22}$; por otro, tan sólo desvelaban su identidad religiosa ante los más próximos, o bien ante aquellos de los que sospechaban que también judaizaban ${ }^{23}$.

Un segundo nivel a considerar es el de los criados, que podían también compartir el criptojudaísmo de sus señores, aunque muchas veces no era así, y tanto en unos casos como en otros su conocimiento (o sospecha) de las prácticas judaizantes a las que se entregaban sus patronos suponía un evidente peligro para éstos; efectivamente, la Inquisición ofrecía a los criados descontentos una magnífica herramienta para ajustar cuentas con sus patronos, a los que podían acusar refugiándose en el anonimato que el Santo Oficio concedía a los testigos. Así, muchos criptojudíos sobornaban o amenazaban a sus criados, para evitar que éstos testificaran contra ellos ante la Inquisición; así lo hizo María Sánchez, mujer de Juan Esteban, que aumentaba el sueldo y prometía otras ventajas materiales a sus criadas si no la denunciaban ante el Santo Oficio ${ }^{24}$.

No sólo eso: muchos conversos, aun no siendo criptojudíos, vivían atemorizados ante la posibilidad de que antiguos criados con los que habían acabado mal, o con los que habían mantenido una relación conflictiva, terminaran testificando en falso contra ellos. Por ese motivo, muchos cristianos nuevos, cuando se enfrentaban a un proceso inquisitorial, incluían en sus tachas los nombres de esos criados susceptibles de haber declarado contra ellos. Alfonso Díaz, vecino de Guadarrama, localidad de la que era alcalde, tachó, entre otros, a su antiguo criado Juan de Antona, al que había tenido que escarmentar en varias ocasiones porque no 
Unir y separar: Algunos efectos socio-religiosos...

cumplía bien con su trabajo; además, Antona había demostrado con creces que odiaba al que antaño había sido su patrono, llegando, incluso, a amenazar con denunciarle a los inquisidores. Igualmente, tachó a una antigua criada cuyo nombre nơ recordaba, hija de Andrés Cambronero, vecino de Collado Mediano, a la que expulsó de su casa sin pagarle la soldada acordada, tras descubrir que le estaba robando ${ }^{25}$.

Era frecuente que los criptojudíos se inventaran mil estratagemas para justificarse ante sus criados, o para que éstos no observaran sus prácticas mosaicas; Marina Alfonso, mujer de Fernando Alonso, contaba en su proceso inquisitorial cómo cuando murió Mayor, mujer de Diego de Pareja, ella y las otras judaizantes que prepararon a la difunta según el ritual judío se las ingeniaron para que la criada saliera de la habitación en la que se efectuaron esos ritos ${ }^{26}$. Por su parte, María Sánchez, mujer de Juan Esteban, justificaba la holganza de los sábados afirmando que ese día había que dedicarlo a la Virgen María ${ }^{27}$. Pero también hay ejemplos en sentido contrario: criados que trataron de influenciar a sus señores para que practicaran los ritos mosaicos; entre ellos, Juan de Tarragona, que mientras trabajaba en Madrid para María Díaz y su marido, Gonzalo Palometa, pretendió convencer a la mujer para que hiciera los ayunos judaicos y diera limosna a hebreos necesitados ${ }^{28}$.

Asimismo, para los judaizantes era muy importante el anudamiento de fuertes lazos con los vecinos que compartían sus creencias religiosas. Esos lazos permitían el mutuo encubrimiento, así como la justificación de muchos comportamientos que podían resultar extraños a los ojos de los cristianos viejos, aunque también implicaban un evidente peligro, pues la caída de uno de los miembros de esos círculos de solidaridad podía arrastrar a todos los que con él habían compartido la realización de ritos $\mathrm{y}$ ceremonias mosaicàs.

Por ejemplo, María Álvarez, mujer de Luis de la Hoz y vecina de Ocaña, envió la típica comida funeraria judía al sastre Gutierre de Toledo cuando murió el hijo de este último ${ }^{29}$; un comportamiento de este tipo tiene una fácil explicación: el sastre podía cumplir con el rito mosaico, pero la comida no se elaboraba en su casa, sino que se traía de fuera, lo que aliviaba un tanto la peligrosidad de la situación. Otro ejemplo: María Sánchez, mujer de Diego Sánchez, vendía queso fresco durante las Cuaresmas a los otros criptojudíos, a escondidas, para que así pudieran consumirlo sin que sus convecinos cristianos viejos lo supieran ${ }^{30}$.

Ante los problemas derivados del mantenimiento de relaciones con los judíos, o los que surgieron como consecuencia de la expulsión de 1492, al- 
gunos conversos efectuaban tareas de contenido ritual con las que prestaban importantes servicios a los otros que formaban parte de su círculo criptojudío. Por ejemplo, en Guadalupe, al menos durante los años centrales de la década de los ochenta, el zapatero Alonso González se encargaba de matar las reses al modo judaico para aquellos cristianos nuevos que judaizaban, tal como consta en el proceso contra Andrés Alonso Trujillano ${ }^{31}$. También los hubo que actuaron como rabinos, convirtiendo sus casas en improvisadas sinagogas; peculiar es el caso de María o Catalina (el proceso se refiere a ella con ambos nombres) Sánchez, a la que los inquisidores acusan de ser «buena heresiarca e rabiça» ${ }^{32}$.

El problema es que de los vecinos con los que se compartían las prácticas criptojudías podía venir la ayuda y el apoyo fundamentales para el mantenimiento de los círculos judaizantes, pero también el fuego de la Inquisición, cuando alguno de ellos era sometido a proceso y optaba por contar lo que sabía de otros. María Alfonso, mujer de Ruy García y vecina de Herrera, acusó a varios conversos con los que había compartido prácticas criptojudías: Diego Gómez y su mujer, ya difuntos cuando los denunció; Lope Alonso; Rodrigo y Gracia de la Peña; la mujer del herrero Antón Ruiz; Pedro Flores; Juana López, mujer del carpintero Antonio Martínez; Clara, mujer de Gonzalo de Chillón. Tampoco se libraron sus propios padres, que habían fallecido tiempo atrás, a los que acusó de haberla impuesto en sus prácticas heréticas ${ }^{33}$.

Cierto es que muchos judaizantes, enfrentados al amargo trance de un proceso inquisitorial, optaron por no denunciar a aquellos con los que habían compartido prácticas criptojudías, tratando de protegerles frente a la acción del Santo Oficio; de modo que era habitual que los fiscales acusaran a los reos de callar lo que sabían de otros herejes, como sucedió durante los procesos de Catalina Sánchez ${ }^{34}$ o de Alfonso Núñez de Sevi$11 a^{35}$.

En cualquier caso, el temor a las delaciones de aquellos con los que se habían compartido prácticas judaizantes era muy evidente. Así, era habitual que los reos, en sus pliegos de tachas, trataran de recusar los posibles testimonios de esas personas que, en otro tiempo, les habían ayudado a practicar el mosaísmo. Por ejemplo, Leonor Díaz, mujer de Arias Díaz, tachó a Elvira González, mujer de Diego Sánchez y presa por la inquisición de Córdoba, alegando que habían existido entre ambas muchas pendencias, motivadas por causas familiares y económicas. También tachó a un nutrido grupo de conversos, encabezados por Ruy Sánchez, cuya mujer había sido quemada por el Santo Oficio, corriendo el rumor 
Unir y separar: Algunos efectos socio-religiosos...

de que había sido Inés González, tía de Leonor, quien la había mandado a la hoguera con su testimonio; por si eso fuera poco, varias mujeres de la familia de Ruy Sánchez habían compartido la prisión inquisitorial con dos hermanas de Leonor, siendo protagonistas de numerosas rencillas. Asimismo, Leonor tachó al matrimonio formado por Diego y Leonor Álvarez, igualmente presos por el Santo Oficio, alegando que eran malas personas, y que además habían reñido con su marido cuando éste les echó de la casa en que vivían, que era de su propiedad, como tachó a otros conversos que tuvieron, igualmente, problemas con la Inquisición, cuyos nombres y circunstancias no se citan para no alargar en exceso esta enumeración ${ }^{36}$.

En la misma línea están las acerbas críticas a las que se tuvieron que enfrentar muchos de los conversos que se reconciliaban, o que expresaban la intención de hacerlo, pues sus reconciliaciones eran una evidente fuente de peligro para los que con ellos había judaizado. Así, por ejemplo, María Sánchez, mujer de Diego Sánchez, afeaba su proceder a todos los cristianos nuevos que acudían a confesar sus pecados ante los inquisidores $^{37}$. En ocasiones, algunos conversos optaron por ponerse de acuerdo a la hora de efectuar sus reconciliaciones, para de esa manera reducir sus consecuencias negativas; tal parece deducirse del proceso de Elvira Núñez, que decidió confesar ante el Santo Oficio los contenidos de una conversación que había mantenido con Francisco Sorge, sólo después de acordar con éste que él también acudiría a los inquisidores a hacer lo propio $^{38}$.

A eso se unió también el afán por disimular las propias creencias, tratando de hacerse pasar por fieles cristianos, en un intento desesperado por apartar las sospechas de sus convecinos cristianos viejos. Así, la pareja formada por María y Juan Sánchez compraron, una vez que se inició la actividad del Santo Oficio, un par de imágenes religiosas, que fueron colocadas en un lugar muy visible de su casa ${ }^{39}$. Similar fue la experiencia de Garci Sánchez, que iba a Misa y recibía los Sacramentos tan sólo para acallar las murmuraciones de sus vecinos ${ }^{40}$.

Durante las primeras etapas de la existencia de las comunidades criptojudías tuvo también mucha importancia el establecimiento de estrechos vínculos con los judíos, que ayudaban a los falsos conversos a practicar los ritos mosaicos, prestándoles apoyo y asesoramiento. La lectura de los procesos inquisitoriales conservados en relación con el reinado de los Reyes Católicos demuestra fehacientemente las relaciones que unieron a judíos y criptojudíos, que tuvieron mucho que ver con la decisión de 
expulsar a los hebreos de los reinos sobre los que gobernaban Isabel y Fernando $^{41}$.

Por otra parte, también es cierto que algunos conversos, independientemente de que fueran criptojudíos o no, se movían como peces en el agua en los círculos judíos, relacionándose muy poco con los otros cristianos. Entre ellos, Elvira, vecina de Talamanca y mujer del tundidor Alonso López, cuyo proceso inquisitorial terminó en absolución, gracias a la fortaleza con la que la mujer se enfrentó a la tortura ${ }^{42}$. Entre sus amigas se contaban varias judías, con las que compartía confidencias y quehaceres domésticos, marcados a veces estos últimos por el cumplimiento de los ritos y preceptos del judaísmo. En efecto, la conversa hubo de reconocer que cuando la hebrea Ceti, mujer de Jacob Gabay, cocinaba pierna de cordero, era la conversa la que le quitaba la landrecilla, pero no lo hacía por ceremonia, sino simplemente porque Ceti no sabía hacerlo bien. Elvira también se vió obligada a admitir que los judíos visitaban habitualmente su casa, pero lo justificó diciendo que todos sus vecinos eran hebreos, y que además en Talamanca los cristianos solían tener esa deferencia con sus vecinos judíos.

En el proceso incoado contra María Álvarez, mujer de Luis de la Hoz, se puede comprobar hasta qué punto muchos criptojudíos dependían del apoyo que les prestaban los hebreos. María mantenía una estrecha relación con Abraham Baqués, que era el que se encargaba de cocerle el pan cenceño, de degollarle los pollos siguiento el rito judío, de informarla de todo lo relativo a los ayunos mosaicos, e incluso era igualmente él quien se encargaba de llevar a la sinagoga el aceite que María entregaba en concepto de donativo. Pero es que la mujer también estaba vinculada con Menahén Moreno, que repartía las limosnas que María destinaba a los menesterosos judíos de su localidad, Ocaña, llevándole carne muerta según el rito judío, cociéndole asimismo a veces el pan cenceño ${ }^{43}$.

Por otra parte, no se puede olvidar que bastantes conversos estaban vinculados por lazos familiares con judíos, lo que contribuía a complicar aun más las cosas, pues muchos de ellos no estaban dispuestos a cortar esos vínculos, que les podían ocasionar muchos quebraderos de cabeza. Por ejemplo, el escribano público Juan de Toledo tenía varios parientes judíos, entre ellos una mujer que le visitaba de vez en cuando; en el transcurso de una de esas visitas, el escribano hizo degollar una gallina al modo judaico para que su pariente pudiera comer de ella, y el resto de la familia hizo lo propio, algo que no pasó desapercibido a sus convecinos cristianos viejos. Pero eso no era todo: dotó a una judía, que era pobre, 
Unir y separar: Algunos efectos socio-religiosos...

para que pudiera casarse con un marido adecuado; posiblemente, también era familiar suya ${ }^{44}$. Similar fue la situación que se vivió en casa de Juan de Sevilla, pues durante mucho tiempo estuvo alojada en ella una hija de su mujer, habida en su primer matrimono, que se mantenía fiel al judaísmo ${ }^{45}$.

Cierto es que las relaciones entre judíos y judaizantes no siempre estuvieron presididas por la armonía; un buen ejemplo en este sentido es él caso de la ya aludida María Álvarez, mujer de Luis de la Hoz, que hubo de enfrentarse a los testimonios incriminatorios de los dos hebreos que durante años la habían ayudado a cumplir con el judaísmo. María tuvo la fortuna de pasar en silencio el terrible trance del tormento que le hicieron aplicar los inquisidores ante las dudas que planteaba su caso, pues ofreció indicios de que tanto los dos judíos como otros testigos que habían declarado contra ella lo habían hecho llevados por la enemistad y la mala fe.

María logró la absolución, pero fueron muchos los conversos que acabaron en la hoguera como consecuencia de testimonios prestados por los hebreos que en su momento les habían dado su apoyo. Porque hubo muchos judíos que, igual que los criados descontentos, aprovecharon el quehacer inquisitorial para ajustar cuentas con aquellos conversos con los que habían tenido pendencias y rencillas, en virtud de unas denuncias que no siempre respondían a la verdad, y refugiándose en el socorrido anonimato de que disfrutaban los que acudían a testificar ante el Santo Oficio.

\section{Unir: el intento de crear una nueva solidaridad entre cristianos nuevos y viejos}

Tal como se ha puesto de relieve en las páginas precedentes, la Inquisición luchó por quebrantar los vínculos de solidaridad que unían a los criptojudíos, trató de convencerles de que no podían fiarse de nadie: los judíos, los criados, los vecinos con los que tantas veces habían compartido prácticas judaizantes, incluso los parientes más cercanos y queridos, podían actuar como instrumentos del Santo Oficio. Pero eso no era suficiente, no bastaba con desunir a los criptojudíos, era necesario dar un paso más: lograr que aquéllos comprendieran que su opción religiosa carecía de futuro, que debían abrazar lealmente el cristianismo. Por supuesto, ese objetivo implicaba crear una nueva solidaridad entre cristianos viejos y nuevos. 
Un objetivo no precisamente fácil de conseguir, problemático incluso para aquellos conversos que, ajenos al criptojudaísmo, lucharon desde el primer momento por lograr su plena integración en la sociedad cristiana. Muchas veces, se vieron rechazados por los cristianos viejos, que estaban dispuestos a sospechar de todos los cristianos nuevos, a considerar que todos ellos eran judaizantes ${ }^{46}$. La lectura de las fuentes permite rastrear numerosos testimonios de la desconfianza que los cristianos viejos sentían hacia los nuevos. Por ejemplo, cuando los inquisidores interrogaron a la cristiana vieja Isabel Ruiz acerca de la ortodoxia de la conversa Catalina Sánchez, Isabel no dudó a la hora de afirmar que «en su pensamiento tenía conçepto que ella e todos los otros conversos no eran buenos christianos ${ }^{47}$. Esa opinión parecía compartirla plenamente el cura Pedro Martínez, que, preguntado por la ortodoxia del cristiano nuevo Diego de Alba, emitió una venenosa declaración, que no le comprometía a nada, pero que podía comprometer, y mucho, al desafortunado converso, pues dijo que aunque siempre le había visto comportarse como buen cristiano «en su casa bien podía faser lo que quisiese»"

Bien es verdad que no todos los cristianos viejos eran depositarios de tales prejuicios hacia los conversos: también los había capaces de huir de generalizaciones siempre exageradas, discerniendo entre los que eran criptojudíos y los que no. Así, en el citado proceso del licenciado Diego de Alba también se recogió la declaración del regidor de Cuéllar Gil Sánchez, al que los inquisidores trataron de poner en apuros, preguntándole si «en secreto sy podiera el dicho liçençiado tener e faser algunas cosas que este testigo no las supiese», a lo que el regidor contestó «que no, porque entre este testigo y el dicho liçençiado avía tal amistad y conversaçión que ninguna cosa fazía, ninguna, que lo non sabía él».

La hostilidad de los cristianos viejos hacia los nuevos no sólo estaba determinada por factores religiosos, por la repugnancia que les causaba la desviada actitud religiosa de muchos conversos, sino también por un incipiente racismo, evidente en casos como el de un clérigo de identidad desconocida, hijo del vecino de Agudo Alonso Carrasco, que saludó con alegría el establecimiento del Santo Oficio, afirmando que «agora verná la ynquisiçión, non quedará confeso ninguno, nin malo nin bueno» ${ }^{49}$. Como resulta evidente, el clero no era ajeno a estas opiniones, incluso parece irrefutable que, en algunos casos, hizo todo lo posible por alentarla. De sobra es conocido el antisemitismo de fray Alonso de Espina, canalizado más contra los cristianos nuevos que contra los propios judíos ${ }^{50}$, como también es perfectamente conocida la hostilidad que sentía hacia los conversos el capellán y cronista de los Reyes Católicos Andrés Bernál- 
Unir y separar: Algunos efectos socio-religiosos...

$\mathrm{dez}^{51}$. Pero parece claro que esas opiniones también encontraron cabida entre el bajo clero, tanto secular como regular, que estaba en estrecho contacto con la gran masa cristiano vieja, y que, precisamente por ese motivo, tenía sobre ella una gran capacidad de influencia.

Se pueden aducir algunos ejemplos en este sentido. Entre otros, el referido a cierto fraile de Alcalá de Henares, que suscitó las quejas de los que, después de abandonar la localidad como consecuencia de la expulsión de 1492, regresaban a ella ya cristianos, para encontrarse con la hostilidad de sus convecinos, atizada por las predicaciones del fogoso fraile ${ }^{52}$. A similares circunstancias hubieron de enfrentarse los que retornaron a Guadalajara, que se toparon con la animosidad del párroco de la iglesia de Santiago, que también acostumbraba dedicar sus más vehementes sermones a los conversos, haciendo blanco sobre todo en aquellos que más recientemente habían abrazado el cristianismo ${ }^{53}$.

El panorama se hizo aun más complejo con la aparición y extensión de los estatutos de limpieza de sangre, circunstancia que contribuyó a dificultar la asimilación de los conversos, pues hizo surgir una evidente (y comprensible, por los problemas futuros que podía acarrear) oposición hacia los matrimonios mixtos. Si en algunos casos simplemente funcionaron los prejuicios contra los cristianos nuevos, en otros da la impresión de que había algo más, como sucedió cuando el doctor de Madrid, vecino de dicha localidad, se negó a casar a una hija suya con su convecino converso Fernando Contador. Cuando ya estaba todo arreglado, un problema con la «escritura de casamiento» dio al traste con la boda: como era habitual, la citada escritura iba encabezada por una invocación religiosa, concretamente de carácter mariano, que Fernando Contador hizo quitar porque no era de su gusto. El cambio preocupó sobremanera al que habría sido su suegro, pues empezó a sospechar que podía ser indicio de criptojudaísmo, así que decidió buscar para su hija otro marido, cuya familia no despertara ese tipo de sospechas ${ }^{54}$.

Muchos cristianos viejos se valieron también de la Inquisición para ajustar cuentas con sus enemigos conversos, sin importarles demasiado si las acusaciones que emitían ante los inquisidores eran ciertas o no, tampoco las consecuencias que podían tener esas acusaciones. De modo que muchos cristianos nuevos procesados por el Santo Oficio incluían en sus pliegos de tachas a aquellos cristianos viejos que temían que les pudieran haber acusado falsamente a la Inquisición. Así, el escribano Ruy González, vecino de Ocaña, tachó a Juan González de la Vega, con el que había tenido varias pendencias, porque éste se vanagloriaba de que iba 
a perder al converso, acudiendo a los inquisidores para declarar contra él ${ }^{55}$.

En esas circunstancias, la integración plena de los conversos en la sociedad cristiana se hacía muy difícil, incluso cuando eran los propios conversos los que ponían todos los medios a su alcance para conseguirla. Esos conversos, que eran fieles cristianos, o que al menos no eran criptojudíos, podían terminar inmersos en unas circunstancias especialmente complejas, porque no eran aceptados por los cristianos viejos, pero habían cortado los lazos con aquellos cristianos nuevos que eran judaizantes, así como con aquellos otros que, aun no siéndolo, estaban poseidos de un fuerte orgullo de raza, que les impulsaba a mantener las distancias con los cristianos viejos ${ }^{56}$. En esos casos, se había cercenado una solidaridad, pero no se había creado otra nueva, y muchas veces el resultado final era el aislamiento, y, quizá también, el arrepentimiento por haber dado la espalda a las creencias de sus mayores.

Muchos de esos conversos creyeron que una buena forma de tratar de obtener la ansiada asimilación era hacer gala de su firme adhesión al cristianismo, a través de una auténtica acumulación de prácticas piadosas y devocionales que parecen estar poseidas de un fuerte exhibicionismo. Frecuentemente, esas prácticas se veían también acompañadas por el público y vehemente despreció hacia los cristianos nuevos que estaban en una posición más difícil, como era el caso de aquellos que habían tropezado con la Inquisición, o los que habían abrazado el cristianismo como consecuencia de la expulsión de 1492.

Así, el varias veces aludido Diego de Alba demostró que los prejuicios no eran prerrogativa exclusiva de un número importante de cristianos viejos, pues también anidaban entre los conversos; tratando de desacreditar a los testigos que habían declarado contra él, y sabiendo que entre ellos había algún judío convertido como consecuencia de los acontecimientos de 1492, afirmó que esos testimonios incriminatorios eran de «personas viles, rraezes e baxas, judios tornadizos o mugeres malas» ${ }^{57}$. Alonso Rodríguez de Seseña también despreciaba a los que se tornaron cristianos tras el edicto de expulsión: durante una pelea con Francisco Mesonero le recordó que había sido judío, empleando esa palabra como insulto y lo mismo hizo cuando disputó con un sastre de Barajas, cuyo nombre ni siquiera recordaba, de modo que cuando tachó su posible testimonio se refirió a él como «un tornadizo de Baraxas»; su mal carácter también le hizo afrentar a Luis Sanz, recordándole su reconciliación por el Santo Oficio ${ }^{58}$. 
Unir y separar: Algunos efectos socio-religiosos...

Por su parte, el zapatero Andrés Alonso, vecino de Belalcázar, tenía entre sus enemigos a García Cabezas, vecino de Herrera, con el que había tenido muchas pendencias y disputas. Esos problemas culminaron cuando el zapatero le vio ataviado con el sambenito que le habían impuesto los inquisidores, lo que le causó una gran hilaridad, que enojó de tal forma a García de Cabezas que le prometió que se vengaría de él, usando la Inquisición como instrumento ${ }^{59}$. Estos ejemplos, y otros muchos que se podrían citar, indican hasta qué punto se había producido una ruptura entre los propios conversos, que habían quedado escindidos en dos grupos: aquéllos que aspiraban, por encima de todo, a integrarse en la sociedad cristiana, mezclándose con los cristianos viejos; aquéllos otros que preferían mantener sus peculiaridades, lo que implicaba una integración parcial en la sociedad cristiana, así como el mantenimiento de las distancias con los cristianos viejos.

Porque, en efecto, algunos conversos (habitualmente criptojudíos) no eran muy proclives al trato con los cristianos viejos, y mucho menos a establecer vinculaciones familiares con ellos. Tal le sucedía al vecino de Ciudad Real Juan Falcón, el Viejo ${ }^{60}$, o a Francisco de Toledo, que se ufanaba de ser enemigo de los cristianos viejos ${ }^{61}$. Un último ejemplo, el de Garci Sánchez, que opinaba que los conversos no debían casar con cristianos viejos ${ }^{62}$.

En estas circunstancias, crear unos potentes lazos de solidaridad entre cristianos viejos y nuevos era algo muy difícil de conseguir, pues se topaba con resistencias por ambos lados; y aunque también por ambos lados existía voluntad de lograr la unión, parece que la mayoría se obstinaba en lo contrario. Ni siquiera medidas como las auspiciadas por los inquisidores de Granada en 1499 estaban destinadas al éxito.

Dichas medidas fueron dictadas por los inquisidores Martín Ponce y Alfonso de Fuentelsaz ${ }^{63}$, con el objeto de solucionar los problemas que planteaba la presencia en Granada de una importante comunidad conversa, que vivía muy cerrada sobre sí misma, y sobre cuya ortodoxia existían vehementes sospechas. Los conversos tendrían que abandonar el barrio en el que habían residido tradicionalmente para vivir mezclados con los cristianos viejos, cuya conversación y ejemplo podría ayudarles a mejorar su instrucción cristiana. La norma debía aplicarse con especial rigor en el caso de aquéllos que habían sido rabinos, que, además, serían apartados de los otros cristianos nuevos. Los curas de las parroquias donde se instalaran conversos tendrían que ocuparse de una forma especial de su adoctrinamiento, asegurándose de que cumplían con los ritos y ce- 
remonias del cristianismo. Los párrocos tendrían que insistir en el adoctrinamiento de los menores de catorce años, quizá porque se consideraba que los jóvenes estarían mejor dispuestos que los adultos a abrazar sinceramente el cristianismo, quizá porque se creía que sus padres y tutores no pondrían el debido interés en su educación cristiana.

El problema es que el cumplimiento de estas normas exigía la colaboración de toda la población cristiana vieja de la ciudad, y en especial de los clérigos. Y está claro que esa colaboración no debió de producirse, pues muchos cristianos viejos residentes en Granada, y entre ellos muchos clérigos, debieron de considerar que tratar de conseguir que los conversos fueran buenos cristianos era una tarea imposible. Sin olvidar que muchos conversos tampoco debían de estar bien dispuestos a convertirse en buenos cristianos... En cualquier caso, medidas como éstas indican hasta qué punto la Inquisición trataba de fomentar la creación de vínculos de solidaridad entre cristianos viejos y nuevos, una vez que se había empezado a romper la cohesión que hasta ese momento había reinado entre los criptojudíos.

\section{Conclusiones}

Cuando la Inquisición inició su andadura, las comunidades criptojudías estaban atadas por unos vínculos de solidaridad que se asentaban sobre un delicado equilibrio, sumamente fácil de romper. El Santo Oficio pronto empezó a fracturar ese precario equilibrio, señalando a los judaizantes que el único camino que se podía seguir era el de la plena integración en el seno de la sociedad cristiana. Sin embargo, la Inquisición sólo logró sus propósitos a medias: si bien consiguió que los judaizantes se instalaran en el miedo y en la desconfianza, que comprendieran que ya nunca podrían vivir tranquilos, no pudo acabar con el criptojudaísmo, que continuó siendo una realidad.

Tampoco fue capaz de obtener la integración de los conversos en el seno de la sociedad cristiana, pues se topó con las reticencias de muchos cristianos viejos, dispuestos a imaginar lo peor de los nuevos, a considerar que nunca podrían ser buenos cristianos, simplemente por el hecho de llevar sangre judía en sus venas. A las dificultades derivadas de los prejuicios de esos cristianos viejos hay que añadir los obstáculos que pusieron algunos conversos, que tampoco estaban dispuestos a asimilarse, pues deseaban mantener sus peculiaridades. La propia actividad inquisitorial fue un freno para la integración de los conversos en la sociedad 


\section{Unir y separar: Algunos efectos socio-religiosos...}

cristiana, pues contribuía a incrementar la desconfianza hacia los cristianos nuevos, al tiempo que mostraba los peligros que acechaban a aquéllos que habían nacido de matrimonios mixtos.

\section{Notas}

1 Esta investigación se ha realizado dentro del proyecto del Ministerio de Ciencia y Tecnología BHA2002-03388, titulado «La monarquía como conflicto en la corona castellano-leonesa, 1230-1504».

2 Aspecto en el que ya insistió J. Caro Baroja, Los judios en la España Moderna y Contemporánea, 3 vols., Madrid, 1978 ( $2^{\mathrm{a}}$ ed.), vol. I, pp. 416 y ss.

${ }^{3}$ Recuerda P. Huerga Criado, En la raya de Portugal: solidaridad y tensiones en la comunidad judeoconversa, Salamanca, 1993, p. 188, que el judaísmo, como todas las otras religiones, tiene una dimensión colectiva, que se manifiesta a través de la socialización de la fe y de sus manifestaciones externas; los criptojudíos también sientieron la necesidad de mantener el carácter social de sus prácticas religiosas: «como cualquier exteriorización de su fidelidad a la ley de Moisés entrañaba un grave riesgo, las redujeron notablemente, pero no renunciaron a compartirlas, siempre en el ámbito de la clandestinidad», lo que les llevó a crear «un espacio cerrado y marginal de sociabilidad en cuyó interior se comunicaban, dándose mutuo testimonio de su fe y reafirmándose así en ella».

${ }^{4}$ Cuestión que también puso de relieve en su momento J. Caro Baroja, Los judíos..., vol. I., pp. 414 y ss., indicando cómo el secreto iba estrechamente unido al disimulo, aspectos que daban «a la misma religión un contenido místico y a la conducta una dirección, que, en todo, chocaba con la de los cristianos viejos» (p. 416).

5 Parece pertinente traer a colación las palabras de C. Roth, Los judios secretos. Historia de los marranos, Madrid, 1979, que afirmaba, p. 52, que «el judaísmo, aun el menos tradicional, es necesariamente, y en gran medida, una regla de vida, más bien que un simple credo", característica que también compartió, como no podía ser menos, el criptojudaísmo.

${ }^{6}$ Esta consideración, que ya estuvo presente en los momentos finales del siglo XV, fue adquiriendo mayor extensión con el paso del tiempo; de tal modo que, como ha recordado P. Huerga Criado, En la raya..., p. 187, en el siglo XVII «tenía mucha más importancia la intención que el acto... ser buen judío consistía, ente todo, en querer serlo».

7 Una vez más, hay que leer a J. Caro Baroja, Los judíos..., vol. I, pp. 416 y ss. Como ha indicado P. Huerga Criado, En la raya..., p. 51, «la institución familiar tiene una extraordinaria importancia, pues a través de sus vínculos se canalizaron los factores que la diferenciaban de la mayoría. Pero también en su seno se produjeron los procesos que tendían a asimilarla a esa mayoría, impidiendo que se desgajara totalmente de ella y haciéndola colaborar en la reproducción del orden social imperante, de cuyos valores dominantes participaba en gran parte».

8 J. Caro Baroja, Los judíos..., p. 420, ha afirmado que a partir de cierto momento «no siempre el parentesco era considerado como vínculo suficiente para confiar las creencias religiosas».

9 Estos datos han sido entresacados de los procesos a los que fueron sometidos Aldonza Núñez y Pedro Núñez, Archivo Histórico Nacional (desde ahora, AHT), Inquisición de Toledo (desde ahora, IT), lg. $168 \mathrm{n}^{\circ} 5$ y lg. $168, \mathrm{n}^{\circ} 7$, respectivamente. 


\section{María del Pilar Rábade Obradó}

10 AHN, IT, lg. 174, $\mathrm{n}^{\circ} 11$.

11 AHN, IT, lg. 133, $\mathrm{n}^{\circ} 20$.

12 AHN, IT, lg. 134, $\mathrm{n}^{\circ} 19$

13 AHN, IT, lg. 165, $\mathrm{n}^{\circ} 4$.

14 AHN, IT, lg. 180, $\mathrm{n}^{\circ} 18$.

15 Llegaba hasta tal punto que, tal como ha recordado J. Caro Baroja, Los judios..., vol. I, p. 416, muchas veces los matrimonios contraidos por los conversos precisaban de dispensa canónica, debido al estrecho parentesco que ligaba a los cónyuges. P. Huerga Criado, En la raya..., pp. 67-68, ha analizado las causas que motivaron esa endogamia, afirmando que «obedecía a dos factores, uno interno y otro externo. La limpieza de sangre, manejada como valor social por la mayoría cristiano-vieja, obstaculizaba los matrimonios mixtos, de manera que la minoría se veía obligada a reproducirse en su interior", pero también es cierto que la endogamia era considerada «el mecanismo capaz de garantizar la supervivencia del grupo como tal, con sus señas de identidad, ya que de lo contrario, de haber tendido mayoritariamente hacia la exogamia, hubiera resultado su propia disolución». Bien es verdad que Huerga ha recordado que la endogamia no era «una tendencia absolutamente generalizada y uniforme», aunque insistiendo en lo inhabitual del establecimiento de vínculos matrimoniales con cristianos viejos, si bien esta última afirmación habría que matizarla, pues tal vez si esos vínculos no se establecieron no fue sólo por iniciativa de los conversos, ya que muchos cristianos viejos tampoco parecían estar bien dispuestos a contraer matrimonio con los nuevos.

${ }^{16}$ AHN, IT, lg. 185, $\mathrm{n}^{\circ} 12$.

17 AHN, IT, lg. 188, $\mathrm{n}^{\circ} 11$.

18 AHN, IT, lg. 144, $\mathrm{n}^{\circ} 4$.

19 AHN, IT, lg. 180, $\mathrm{n}^{\circ} 10$.

20 AHN, IT, lg. 167, $\mathrm{n}^{\circ} 7$.

21 AHN, IT, lg. $158, \mathrm{n}^{\circ} 5$.

${ }^{22}$ Recuérdese, por ejemplo, el caso, ya mencionado, de Juana Rodríguez, impuesta en el judaísmo a los trece años por su padre.

23 Así, Beatriz Núñez, mujer de Fernando González, aconsejaba continuamente a sus hijos que no se descubrieran ante nadie, pues así estarían más protegidos (AHN, IT, lg. $\left.169, \mathrm{n}^{\circ} 2\right)$.

${ }_{24}$ AHN, IT, lg. 183, $\mathrm{n}^{\circ} 19$.

25 AHN, IT, lg. 141, $\mathrm{n}^{\circ} 5$.

26 AHN, IT, lg. $132, \mathrm{n}^{\circ} 9$.

27 Ver nota $n^{\circ} 24$.

28 AHN, IT, lg. 143, $\mathrm{n}^{\circ} 13$.

29 AHN, IT, lg. 134, $\mathrm{n}^{\mathrm{o}} 2$. Existen algunos estudios sobre la realidad interna de las comunidades criptojudías; entre ellos, hay que destacar el dedicado a la de Ciudad Real por H. Beinart, Los conversos ante el tribunal de la Inquisición, Barcelona, 1983.

${ }^{30} \mathrm{AHN}, \mathrm{IT}, \mathrm{lg} .184, \mathrm{n}^{\circ} 1$.

31 AHN, IT, lg. 132, $\mathrm{n}^{\circ} 18$.

32 AHN, IT, lg. 183, $\mathrm{n}^{\circ} 10$.

33 AHN, IT, lg. 132, no 8.

${ }^{34}$ AHN, IT, lg. 183, $\mathrm{n}^{\circ} 11$.

35 AHN, IT, lg. 168, $\mathrm{n}^{\circ} 6$.

36 AHN, IT, lg. 143, $\mathrm{n}^{\circ} 9$.

37 Ver nota $\mathrm{n}^{\circ} 30$. 


\section{Unir y separar: Algunos efectos socio-religiosos...}

38 AHN, IT, lg. 169, $\mathrm{n}^{\circ} 6$.

39 AHN, IT, lg. 184, $\mathrm{n}^{\circ} 2$..

40 AHN, IT, lg. 183, $\mathrm{n}^{\circ} 15$.

${ }^{41} \mathrm{El}$ decreto de expulsión se manifiesta claramente en ese sentido; ver, por ejemplo, la edición íntegra del texto publicada en A. Alcalá Galve (ed.), Judios. Sefarditas. Conversos. La expulsión de 1492 y sus consecuencias, Valladolid, 1995, pp. 125-133.

42 AHN, IT, lg. 144, $\mathrm{n}^{\circ} 3$.

43 Ver nota $\mathrm{n}^{\circ} 29$.

44 AHN, IT, lg. 185, $\mathrm{n}^{\circ} 9$.

45 AHN, IT, lg. 184, $\mathrm{n}^{\circ} 10$.

46 J. Contreras Contreras, «Judíos, judaizantes y conversos en la Península Ibérica en tiempos de la expulsión", en A. Alcalá Galve (ed.), Judios. Sefarditas..., pp. 457-477, y en concreto p. 458, no ha dudado a la hora de afirmar que «el problema más singular, el que más incidencia tuvo sobre la historia posterior de los reinos hispánicos y de su proyección hacia América no fue el de los judíos ni el de los judaizantes perseguidos por el Santo Oficio, sino el que protagonizaron los conversos intentanto olvidar su origen y buscando penetrar en el horizonte cultural de la mayoría viejocristiana».

47 AHN, IT, lg. 183, $\mathrm{n}^{\circ} 10$.

48 AHN, IT, lg. 133, $\mathrm{n}^{\circ} 7$.

49 AHN, IT, lg. 153, $\mathrm{n}^{\circ} 18$.

${ }^{50}$ Consultar M. P. Rábade Obradó, «Franciscanismo y criptojudaísmo: los orígenes de las Inquisición española», comunicación presentada al Convegno Internazionale di Studi I Francescani e la politica (secc. XIII-XVII), celebrado en Palermo, Monreale y Sciacca en diciembre de 2002 (en prensa).

51 Son bien conocidos los párrafos que les dedica en su crónica, al aludir al establecimiento de la Inquisición; ver A. Bernáldez, Memorias del reinado de los Reyes Católicos, edic. de M. Gómez Moreno y J. de M. Carriazo Arroquia, Madrid, 1962.

52 AGS, RGS, 26-III-1495, Madrid, f. 173.

53 AGS, RGS, 15-V-1495, Madrid, f. 249.

${ }^{54}$ AHN, IT, lg. 139, $\mathrm{n}^{\circ} 14$.

55 AHN, IT, lg. 155, $\mathrm{n}^{\circ} 16$.

56 Según J. Caro Baroja, Los judíos..., vol. I, p. 422, «la endogamia, la estrecha vida familiar y la 'infamia pública' van unidas a un gran orgullo de linaje, un orgullo tan grande como el que podía tener el hidalgo más fiero que decía descender de los godos». Pero este orgullo de raza también estuvo presente entre los conversos sinceros, como Pablo de Santa María, que se vanagloriaba de pertenecer al linaje de Leví, como ha reseñado J. CARO BAROJA, Los judios..., vol. I, p. 422. Los procesos inquisitoriales también arrojan alguna información en ese sentido: por ejemplo, Mencía Suárez no se indignaba de que la llamaran judía, pues siempre recordaba que ella descendía del linaje de Jesucristo y de la Virgen María, no de linaje de paganos (AHN, IT, lg. 158, n 25); Fernando del Parral siempre decía que, aunque tenía parte de cristiano viejo y parte de cristiano nuevo, su mejor parte era esta segunda (AHN, IT, lg. 173, $\left.\mathrm{n}^{\circ} 12\right)$.

57 Ver nota $n^{\circ} 48$.

${ }^{58}$ AHN, IT, lg. 176, $\mathrm{n}^{\circ} 16$

59 AHN, IT, lg. 132, $\mathrm{n}^{\circ} 5$.

60 AHN, IT, lg. 146, $\mathrm{n}^{\circ} 2$.

61 AHN, IT, lg. 185, n 8. 
86

María del Pilar Rábade Obradó

62 Ver nota $\mathrm{n}^{\circ} 40$.

63 Publicadas por J. Meseguer, «Fernando de Talavera, Cisneros y la Inquisición en Granada", en J. Pérez villanueva (ed.), La Inquisición española. Nueva visión, nuevos horizontes, Madrid, 1980, pp. 371-400. 